\title{
LA-UR-17-26084
}

Approved for public release; distribution is unlimited.

Title:

Author(s):

Intended for:

Issued:
RCT: Module 2.11, Radiological Work Coverage, Course 8777

Hillmer, Kurt T.

Training

2017-07-20 
Disclaimer:

Los Alamos National Laboratory, an affirmative action/equal opportunity employer, is operated by the Los Alamos National Security, LLC for the National Nuclear Security Administration of the U.S. Department of Energy under contract DE-AC52-06NA25396. By approving this article, the publisher recognizes that the U.S. Government retains nonexclusive, royalty-free license to publish or reproduce the published form of this contribution, or to allow others to do so, for U.S. Government purposes. Los Alamos National Laboratory requests that the publisher identify this article as work performed under the auspices of the U.S. Department of Energy. Los Alamos National Laboratory strongly supports academic freedom and a researcher's right to publish; as an institution, however, the Laboratory does not endorse the viewpoint of a publication or guarantee its technical correctness. 


\section{RCT: Module 2.11, Radiological Work Coverage Course 8777}

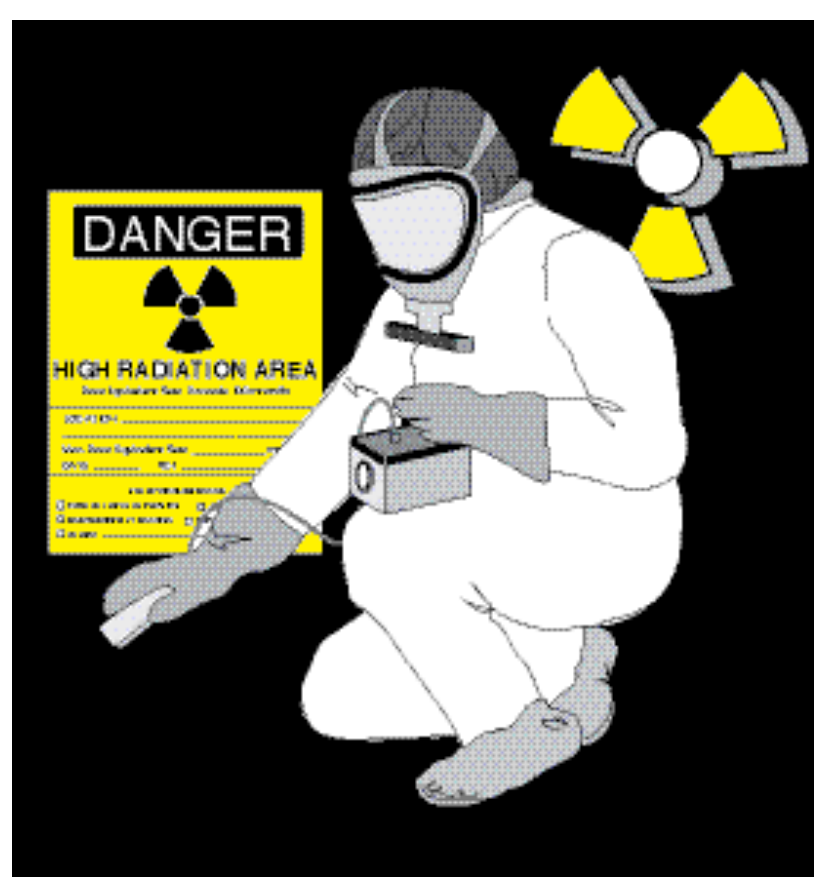

July 2017

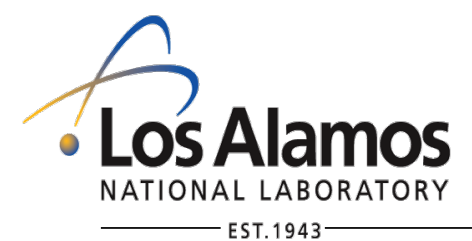

Operated by Los Alamos National Security, LLC for the NNSA 
This training course was prepared by Los Alamos National Security, LLC (LANS) under Contract DE-AC52-06NA25396 with the U.S. Department of Energy, National Nuclear Security Administration (DOE/NNSA). All rights in the material are reserved by DOE and LANS pursuant to the contract. This training course is presented with the understanding that the information and materials provided were developed based on specific circumstances present at the Los Alamos National Laboratory at the time of publication. Those circumstances may or may not be similar to conditions present at other locations represented by participants in this course. The course materials and information will need to be adapted accordingly. NEITHER THE DOE/NNSA, NOR LANS, NOR ANY OF THEIR EMPLOYEES, MAKES ANY WARRANTY, EXPRESS OR IMPLIED, OR ASSUMES ANY LEGAL LIABILITY OR RESPONSIBILITY FOR THE ACCURACY, COMPLETENESS, OR USEFULNESS OF ANY INFORMATION, APPARATUS, PRODUCT, OR PROCESS DISCLOSED AND WILL NOT BE LIABLE FOR DIRECT OR INDIRECT DAMAGES RESULTING FROM USE OF THIS MATERIAL.

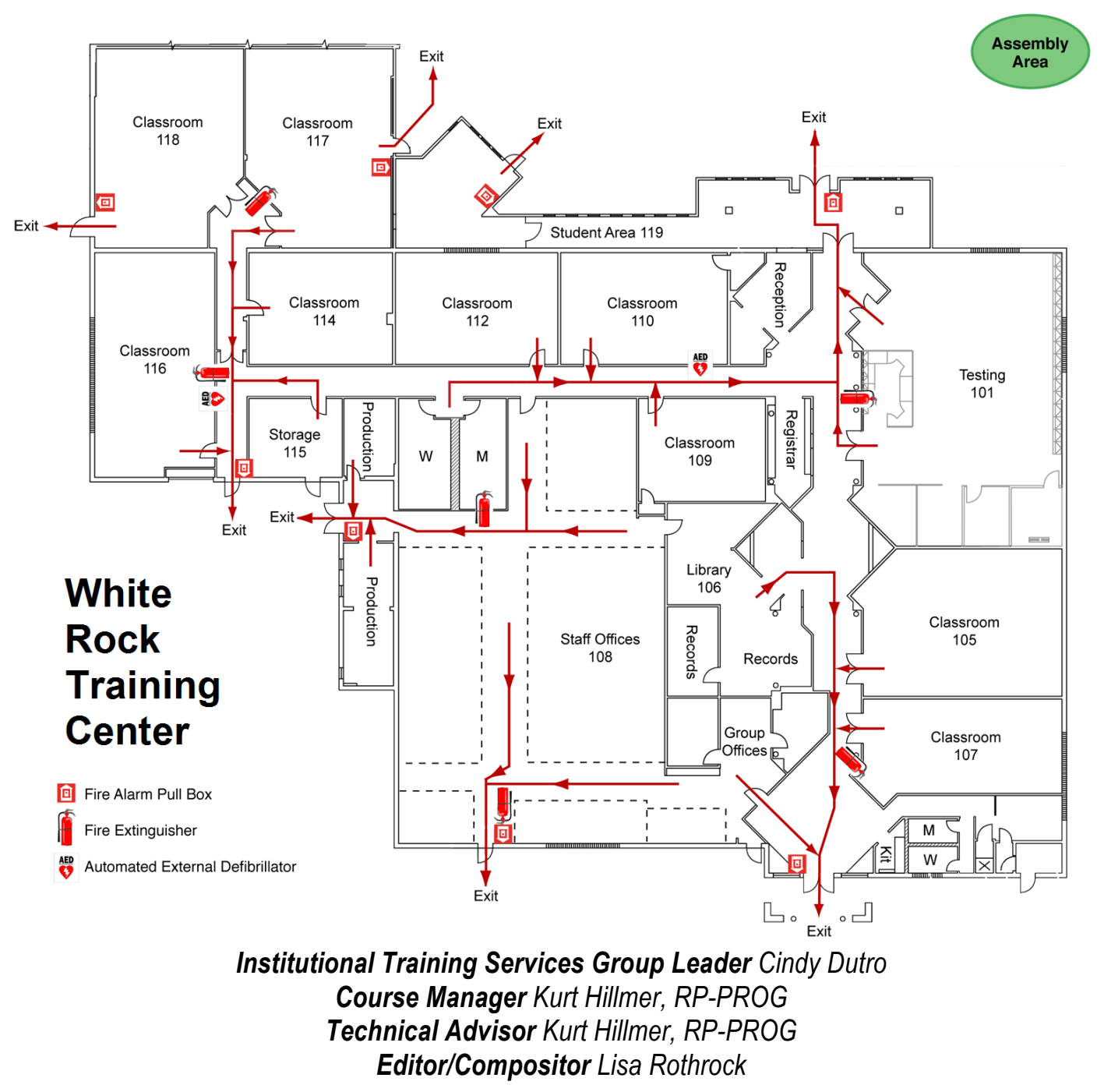

Course Number: 8777

July 2017

LA-UR-17-XXXX

Controlled Document Number: RCT_2.11_Rad-Wk-Cover_8776_SM,R1.1 


\section{Contents}

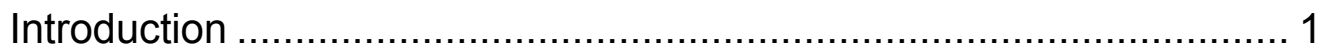

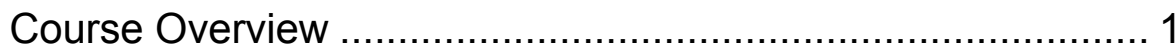

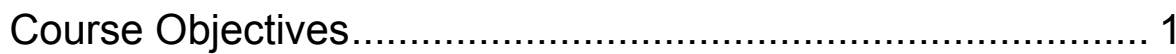

Target Audience

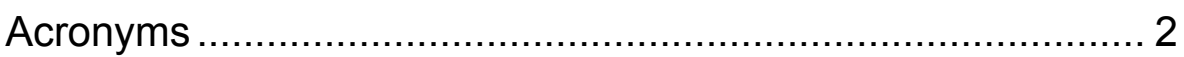

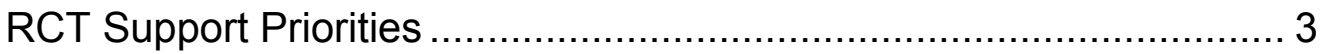

Purpose of RCT Job Coverage .......................................................... 5

Continuous and Intermittent Job Coverage .................................... 7

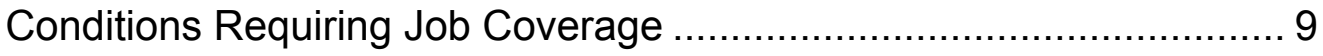

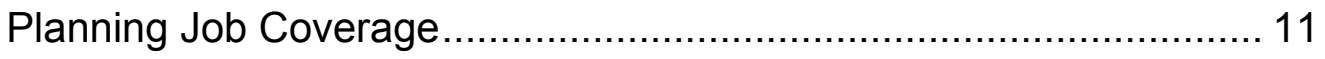

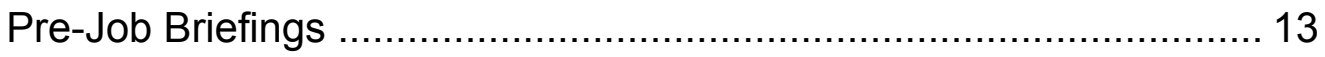

Exposure Control Techniques....................................................... 15

In-Progress Radiological Surveys at LANL .................................... 17

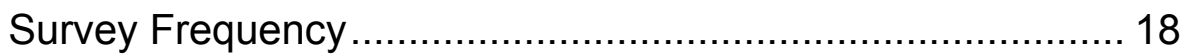

Documentation of In-Progress Radiological Surveys........................ 19

Unexpected Radiological Conditions …....................................... 21

Contamination Control Techniques.............................................. 23

Airborne Radioactivity Control .................................................... 25

Overall Job Control Techniques..................................................... 27

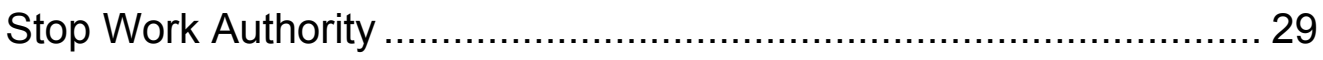


Contents

Notes. . . . 


\section{Introduction}

\section{Course Overview}

Radiological work is usually approved and controlled by radiation protection personnel by using administrative and procedural controls, such as radiological work permits (RWPs). In addition, some jobs will require working in, or will have the potential for creating, very high radiation, contamination, or airborne radioactivity areas.

Radiological control technicians (RCTs) providing job coverage have an integral role in controlling radiological hazards.

This course will prepare the student with the skills necessary for RCT qualification by passing quizzes, tests, and the RCT Comprehensive Phase 1, Unit 2 Examination (TEST 27566) and will provide in-the-field skills.

\section{Course Objectives}

\subsubsection{List four purposes of job coverage.}

2.11.02 Explain the differences between continuous and intermittent job coverage.

2.11.03 Given example conditions, identify those that should require job coverage.

2.11.04 Identify items that should be considered in planning job coverage.

2.11.05 Identify examples of information that should be discussed with workers during pre-job briefings.

2.11.06 Describe exposure control techniques that can be used to control worker and technician radiation exposures.

2.11.07 Describe the in-progress radiological surveys that should be performed at LANL under various radiological conditions.

2.11.08 Describe LANL requirements for documentation of in-progress radiological surveys.

2.11.09 Explain actions that should be taken if surveys show radiological conditions significantly different from that expected. 
2.11.10 Describe contamination control techniques that can be used to limit or prevent personnel and area contamination and/or reduce radioactive waste generation.

2.11.11 Describe job coverage techniques that can be used to prevent or limit the spread of airborne radioactive material.

2.11.12 Describe overall job control techniques in maintaining control of radiological work.

2.11.13 State the reasons to stop radiological work activities in accordance with the DOE radiological control standard (RCS).

\section{Target Audience}

This course is designed for LANL new-hire RCTs with no operational experience.

\section{Acronyms}

$\begin{array}{ll}\text { ALARA } & \text { as-low-as-reasonable achievable } \\ \text { CAM } & \text { continuous air monitor } \\ \text { R2A2 } & \text { roles, responsibilities, authorities, and accountability } \\ \text { RBA } & \text { radiological buffer area } \\ \text { RCS } & \text { radiological control standard } \\ \text { RCT } & \text { radiological control technician } \\ \text { RWP } & \text { radiological work permit }\end{array}$




\section{RCT Support Priorities}

P313, Roles, Responsibilities, Authorities, and Accountability (R2A2) defines R2A2 for all LANL employees.

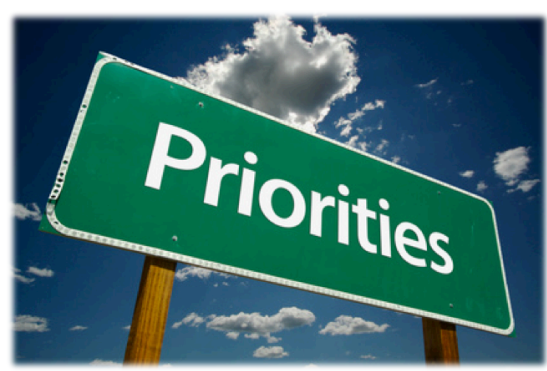

P313, Attachment A, Facility Operations R2A2, indicates the following:

\begin{tabular}{|c|c|}
\hline & Radiological Control Technician (RCT) \\
\hline Role & $\begin{array}{l}\text { The RCT provides radiological support at assigned Laboratory } \\
\text { facilities, including (in priority order): emergency response, } \\
\text { compliance, facility operability, and programmatic activities. }\end{array}$ \\
\hline Responsibility & $\begin{array}{l}\text { - Coordinate with Radiation Protection First Level Manager } \\
\text { and FOD operations and support staff to help plan and } \\
\text { safely execute radiological work in the facility. } \\
\text { - Ensure compliance with RP policies and procedures. } \\
\text { - Work safely and securely; implement safety initiatives (e.g., } \\
\text { conduct peer-to-peer observations to improve safety } \\
\text { performance). } \\
\text { - Implement RP procedures and for a wide range of activities } \\
\text { such as reviewing radiological work for proper controls, } \\
\text { posting, conducting radiological surveillances, contamination } \\
\text { control, and external exposure control, in compliance with } \\
\text { Laboratory requirements. } \\
\text { - Interface with emergency personnel or directly respond to an } \\
\text { emergency situation involving radiation or radioactive } \\
\text { material. } \\
\text { - May develop RWPs as qualified and authorized by } \\
\text { management. } \\
\text { - May be called upon to assume field coordination } \\
\text { responsibility and direct the actions of other technicians. }\end{array}$ \\
\hline Authority & $\begin{array}{l}\text { - Elevate issues as appropriate to the management chain and } \\
\text { ADESH. } \\
\text { - Pause or stop work to ensure work activities are completed } \\
\text { safely. }\end{array}$ \\
\hline Accountability & $\begin{array}{l}\text { - To the Radiation Protection Field Coordinator and Deployed } \\
\text { Services ES\&H Team Leader for day-to-day direction. }\end{array}$ \\
\hline
\end{tabular}


Notes. . . . 


\section{Purpose of RCT Job Coverage}

2.11.01 List four purposes of job coverage.

Job coverage by RCTs generally has four purposes:

- to ensure that worker's radiation exposures are maintained as low as reasonably achievable (ALARA) and within limits/guidelines,

- to minimize the creation and spread of surface contamination,

- to minimize the creation and spread of airborne radioactive material, and

- to minimize the creation of radioactive waste.

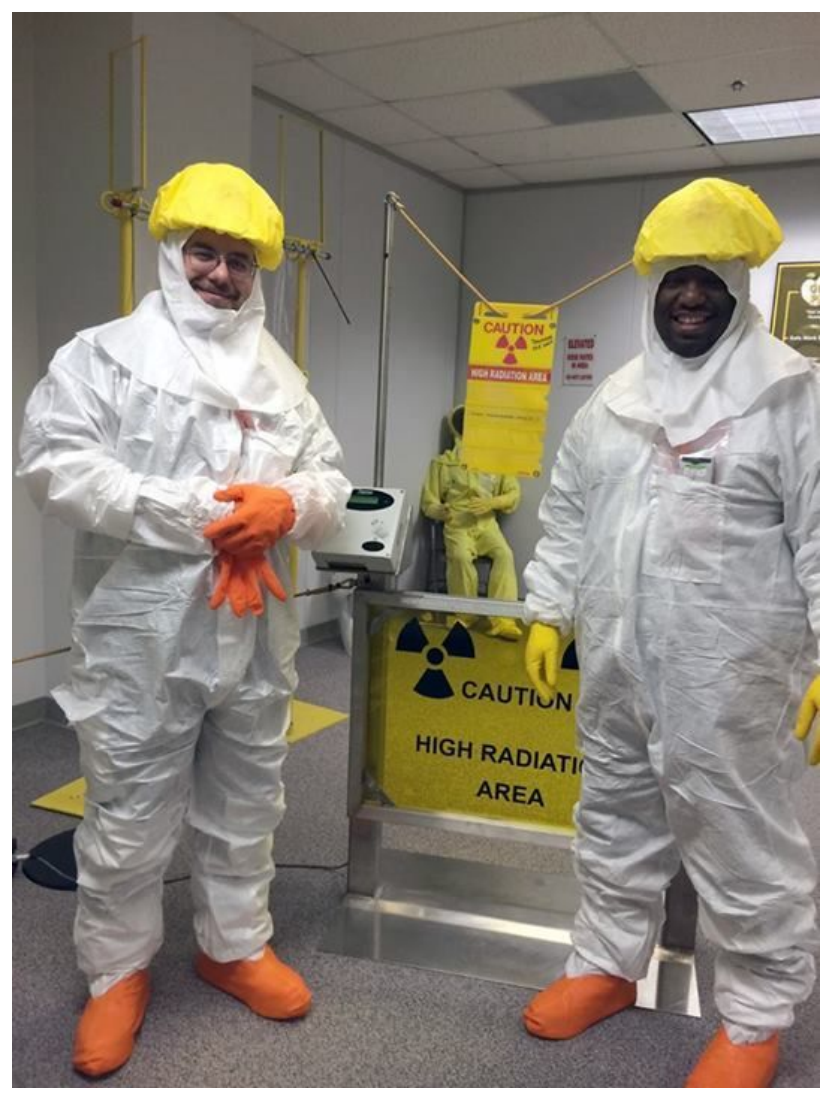




\section{Purpose of RCT Job Coverage}

Notes. . . . 


\section{Continuous and Intermittent Job Coverage}

2.11.02 Explain the differences between continuous and intermittent job coverage.

Job (or work) coverage can be either continuous or intermittent.

- During continuous job coverage, the technician covers only one job and remains at the job site while work is being performed.

- For intermittent coverage, the technician may cover more than one job, performing periodic checks at various work locations. 
Notes. . . . 


\section{Conditions Requiring Job Coverage}

2.11.03 Given example conditions, identify those that should require job coverage.

Continuous radiological job coverage is required in the following areas:

- high radiation area,

- very high radiation area,

- high contamination area,

- airborne radioactivity area, and

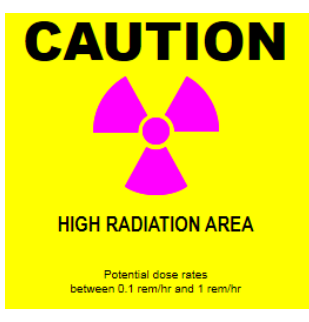

- any areas in which respiratory protection is used for radiation protection purposes.

Continuous radiological job coverage is required for the following:

- Radiation dose rates in the job area that are high enough to potentially cause workers' doses to exceed administrative control levels in a short time.

- Radiation levels that are expected to increase significantly during the job.

- Radiation levels that are unknown before beginning the job.

- Entry into high-radiation areas.

- The potential for spreading high levels of contamination or causing airborne radioactivity.

- The potential for a significant increase in contamination or airborne radioactivity levels during the job.

- Inadequate personnel dosimetry for the type or levels of expected radiation (e.g., neutrons or low-range dosimeters).

- Jobs performed by inexperienced workers or by workers unfamiliar with the area or the job. 
Notes. . . . 


\section{Planning Job Coverage}

2.11.04 Identify items that should be considered in planning job coverage.

To effectively cover a job, RCTs must plan activities. Actions that should be incorporated in the planning include

- determining exactly what workers will be doing;

- reviewing old surveys, and talking with technicians who have previously covered the same or similar jobs to anticipate any problem areas;

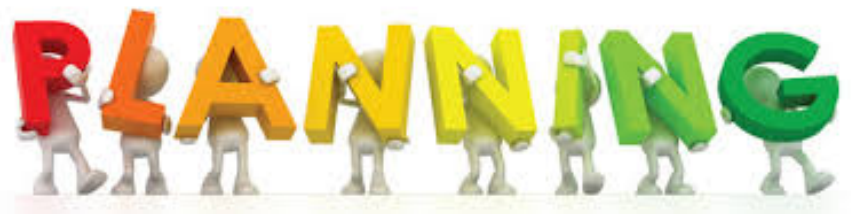

- reviewing the area and system on which the work will be performed, or talking with the workers to determine the potential radiological consequences of the tasks associated with the job;

- ensuring that an adequate survey of the job area has been made;

- reviewing applicable post-job ALARA reviews;

- requiring a pre-job survey when sufficient survey documentation is not available. This detailed survey is performed at the job site before the job begins and is used to determine RWP requirements. This survey should include the dose rate, contamination, and representative breathing zone air samples for the areas being accessed. The survey should identify the highest and lowest dose rate areas;

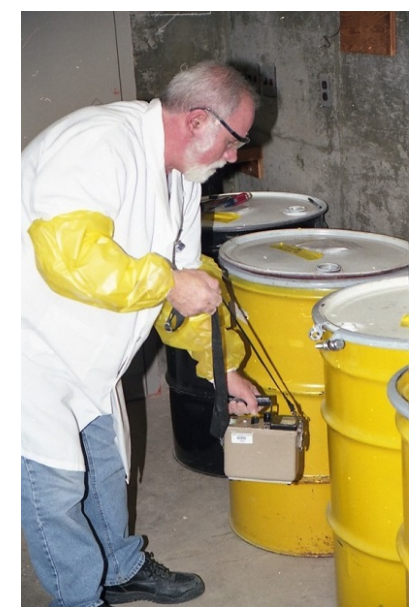


- recording the allowable exposure for each worker for jobs in which workers' dose limits could be approached. A good practice is to have this information available at the job site;

- establishing communication methods with the workers before the job is performed. Workers should know how, when, where, and why to contact the RCT;

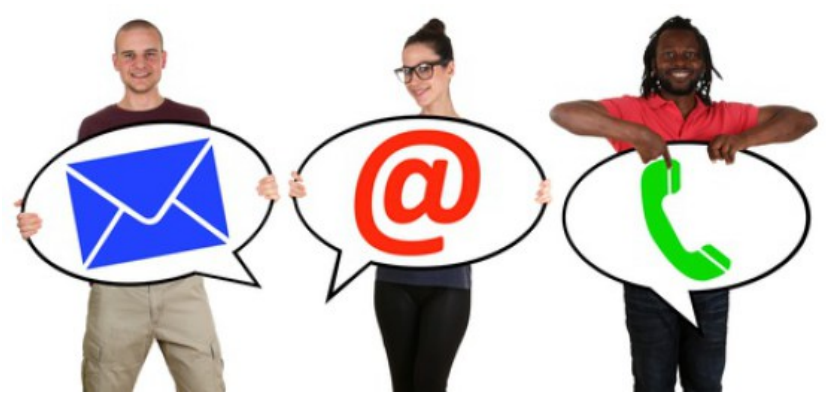

- communicating with workers, which for most jobs is simply a matter of talking face to face. However, for some jobs, remote communications (e.g., headsets, or a safety line attached to a belt) may be required. Hand signals may be needed when respirators are worn. Two-way portable radios also may be used;

- establishing a method of communicating with and transferring samples to the radiological control counting lab;

- arranging for the transfer of samples to the count lab, and obtaining results, which should be made before the job begins;

- having the appropriate equipment available at the job site. Examples include extra dosimeters, a dosimeter charger, air sampler and filters, a survey instrument, a respirator (if needed), a watch or clock for time keeping, and extra gloves; and

- determining waste disposal methods.

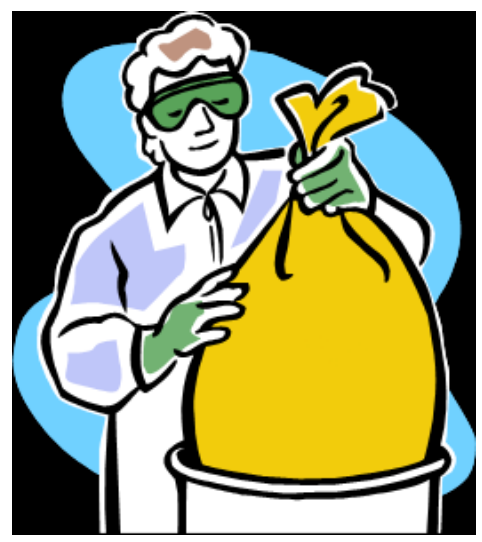




\section{Pre-Job Briefings}

2.11.05 Identify examples of information that should be discussed with workers during pre-job briefings.

Pre-job briefings are conducted by the cognizant RCT and should include the following information:

- the scope of work to be performed;

- radiological conditions, such as dose rates, contamination levels, and the concentration of airborne radioactivity in the work area;

- an explanation of the probable effect of the job on radiological conditions;

- RWPs and special radiological control requirements;

- RWP limits—conditions, such as contamination or radiation levels that may void the RWP;

- health physics/radiological control hold points;

- $\quad$ other important points, which could include the method of communications that will be used, specifics about special dosimetry or protective clothing, and actions of the technician covering the job; and

- actions and exits to take in an emergency to reduce worker exposure and confusion.

Worker questions should be answered before work begins.

The RCT should emphasize radiological safety and the importance of following the RWP and its specific directions. 
Notes. . . . 


\section{Exposure Control Techniques}

2.11.06 Describe exposure control techniques that can be used to control worker and technician radiation exposures.

The techniques in covering a job will depend on the nature of work being done, the radiological conditions present or expected in the work area, and, to some extent, the experience of the workers.

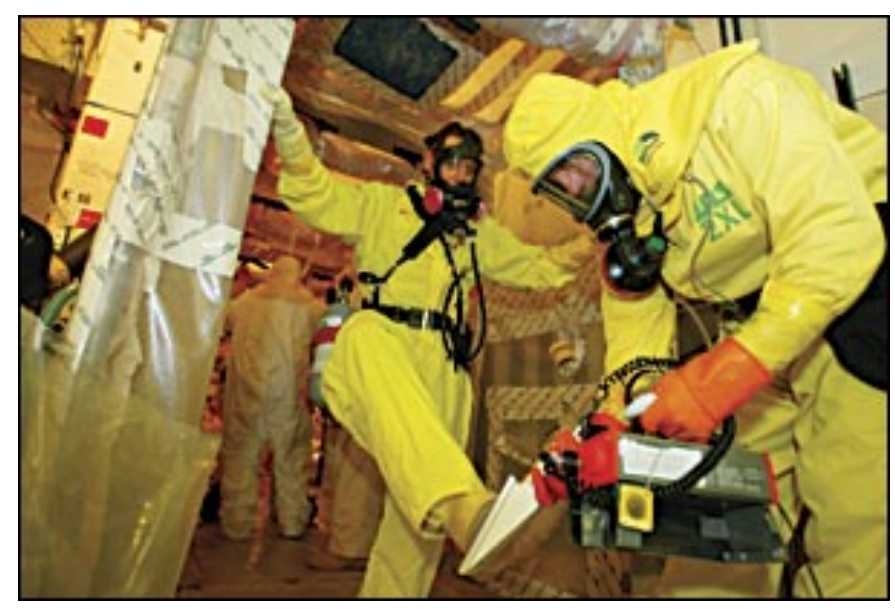

One of the purposes of job coverage is to keep track of the dose received by workers and suggest methods that the workers can follow to keep their doses ALARA. Pre-job surveys alone are not always adequate in determining the dose rates that personnel may acquire during the job. Many jobs will require that surveys be performed as the job progresses.

The purpose and type of surveys should be based on the level of the conditions and their probability of change. Surveys provide information about current conditions and if the conditions are changing; they can identify unusual conditions that may lead to changing job requirements or even stopping the job. It is just as important to record the results of job coverage surveys as recording the results of the routine and pre-job surveys.

Keep personnel in the area informed of the radiological conditions; RCTs should explain to the workers why actions are being taken.

The following is a list of some of the techniques that can be used to help maintain exposure control:

- Wait in low-dose-rate areas when not actually performing the job. 
- Periodically read or have workers read their dosimeters. Use workers' allowable dose and the dose rate in an area to determine the length of time a worker can spend in the area. When using time to control workers' doses, an accurate record of the workers' location with respect to the dose rate must be maintained.

- Write down the workers' location and time in that location when time keeping. Relying on memory can be inaccurate. Record the times in the area.

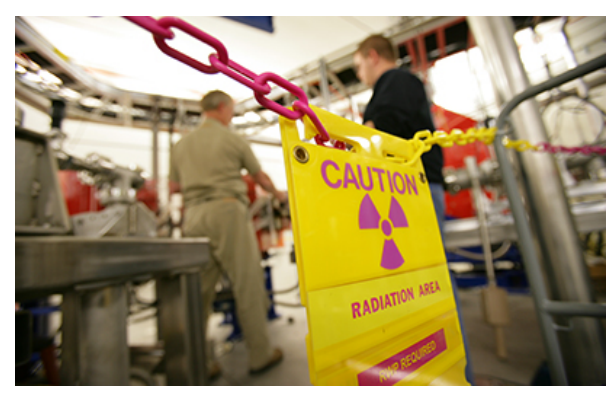

- Observe the location of workers' dosimetry with respect to the location of the radiation source.

- Ensure that workers leave temporary shielding in place unless they have been authorized to remove the shielding by radiological control supervision. Technicians performing job coverage should move temporary shielding only after evaluating the effect of such movement and with proper approval.

- Perform your survey as objects are being removed from their shipping container or cask.

- Keep workers from leaning across or over high sources of radiation.

- Prevent workers from picking up sources of radiation with their hands. Use pliers or tongs, and use buckets or a plastic bag to carry items.

- Any time casks, equipment, or containers are being opened (or opened further than before), recheck radiation levels, including beta radiation levels.

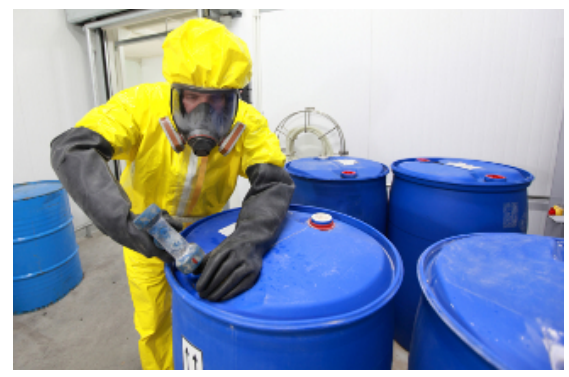




\section{In-Progress Radiological Surveys at LANL}

2.11.07 Describe the in-progress radiological surveys that should be performed, at your site, under various radiological conditions.

In-progress radiological surveys should be performed as specified by the controlling technical work document and RWP. Radiological control programs require the performance of external radiation, airborne radioactivity, and contamination surveys to determine existing conditions in a given location.

Maps with sufficient detail to permit identification of original survey and sampling locations should be maintained by the RCT. Records should contain sufficient detail to be meaningful, even after the originator is no longer available.

Contamination Survey-Contamination surveys characterize workplace conditions, identify areas and/or materials that require radiological posting or labeling, and ensure that no regulated contamination limits are exceeded.

Airborne Radioactivity Survey-Air monitoring is performed based on the potential for radioactive material to become airborne. Operations that can cause material to become airborne include, but are not limited to cutting, grinding, welding, sanding, or spraying.

External Radiation Survey-Radiation surveys provide information concerning external sources of whole-body and/or extremity exposure to personnel.

Survey Frequency Requirements-The survey frequency should be established based on radiological conditions, probability of change in conditions, and occupancy. Surveys should be performed before, during, and after work that could cause significant changes in radiological conditions.

When to Conduct Contamination Surveys-An integral part of the monitoring program is the collection of survey data by contamination surveys of the workplace and the survey of materials and equipment before they are released or transferred from one location to another. 
The primary methods for detecting contamination at the Laboratory are smear surveys, large-area swipe surveys, and direct frisk (including floor monitoring).

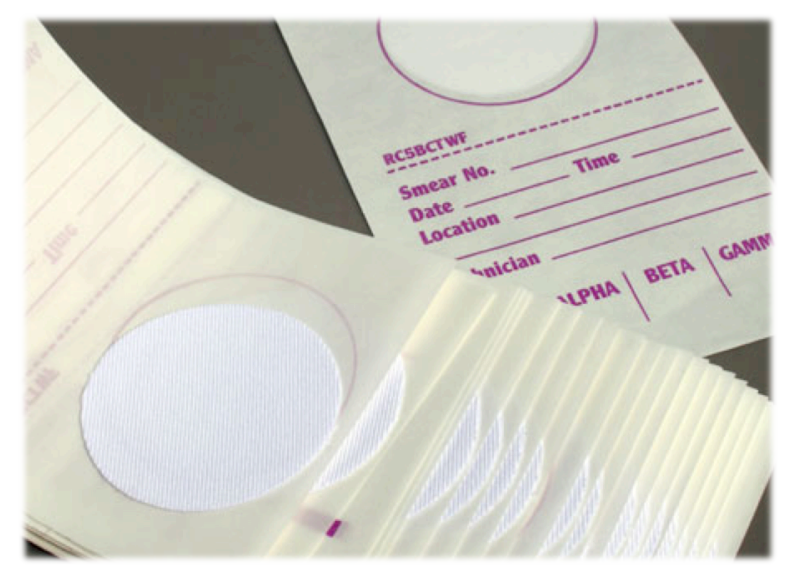

\section{Survey Frequency}

The frequencies of routine contamination surveys are listed in RP-SOP-020, Contamination Monitoring Standard. The following frequencies are required:

- Daily, at contamination area control points, change areas, or step-off pads when in use, or per shift in high-use situations.

- Daily, in office space located in radiological buffer areas (RBAs) established for contamination control.

- Daily, in lunch rooms or eating areas near RBAs established for contamination control.

- Weekly, in routinely occupied RBAs established for contamination control.

- Weekly, or upon entry if entries are less frequent, in areas where radioactive materials are handled or stored.

- During initial entry into known or suspected contamination areas, periodically during work, at completion of job, or as specified in an RWP.

- After a leak or spill of radiological materials.

- Weekly, in areas identified as either being contaminated or having the potential for being contaminated with hot particles, and daily, during periods of work that may result in the generation of hot particles. 


\section{Documentation of In-Progress Radiological Surveys}

2.11.08 Describe site requirements for documentation of in-progress radiological surveys.

Radiological control personnel should maintain logs to document radiological occurrences, status of work activities, and information that should be communicated to all personnel.

Field notes of survey results should be made for later documentation. Good practice dictates that all surveys should, at a minimum, be documented on the appropriate map.

Documentation of radiological surveys includes the following elements:

- date and time,

- locations and map,

- name and signature of the surveyor,

- instrument model and number,

- purpose and reference to a specific RWP if applicable, and

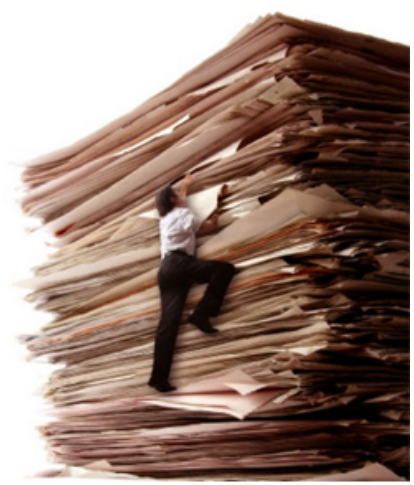

- results.

Documentation for airborne radioactivity surveys includes

- flow rates and

- duration of sampling.

Documenting results is critical, even if no contamination is detected. These documents become part of the Laboratory's permanent record of radiological conditions. Forms must be carefully filled in with all requested information. Any pertinent special notes that would aid the reader in interpreting the results or planning future actions should also be added. 
Notes. . . . 


\section{Unexpected Radiological Conditions}

2.11.09 Explain actions that should be taken if surveys show radiological conditions significantly different from that expected.

If previously undiscovered contamination is detected during contamination surveys, more smears and swipes should be taken so that the extent and levels of the contamination can be determined.

If contamination is detected, direct instrument surveys, large-area-swipe surveys, and/or comprehensive smear surveys are used to delineate the radiological boundaries. Large-area swipes are used to provide a quick estimate of the extent of contamination in a known or suspected contaminated area. New postings may be required for areas with significant readings.

When higher-than-expected levels are found, the RCT should evacuate the area and determine why the rates are higher. If higher radiation levels are indicated, the RCT will investigate the reason for the increase.

If the conditions are different enough to warrant a change in the protection requirements, stop work until the RWP can be revised and approved.

Any radioactive material outside a contamination area must be identified with suitable tags or labels. If you find unlabeled radioactive material in a controlled area, this radiological occurrence must be reported. 
Notes. . . . 


\section{Contamination Control Techniques}

2.11.10 Describe contamination control techniques that can be used to limit or prevent personnel and area contamination and/or reduce radioactive waste generation.

By observing the actual performance of the job, RCTs can suggest methods that could help prevent the spread of contamination from one area to another and could lessen the probability of personnel contamination.

- Watch the workers.

- Wipe down and drain system components that are being repaired before the system is opened.

- Ensure that workers follow procedures for transferring material from the radiological area to either a radiologically controlled area or a clean area.

- Control the removal of equipment from work areas.

- Ensure that workers follow proper procedures to minimize the contamination of tools and equipment.

- Watch for the movement of crane rigging, air or water hoses, electric leads, and extension cords into and out of contaminated areas.

- Secure electrical lines and hoses going into contaminated areas to eliminate the possibility of movement in or out.

- Have workers remove their outer layer of protective clothing a few feet from the step-off pad area.

- Reduce the creation of radioactive waste. 
Notes. . . . 


\section{Airborne Radioactivity Control}

2.11.11 Describe job coverage techniques that can be used to prevent or limit the spread of airborne radioactive material.

When the creation and spread of airborne radioactivity can be controlled, the use of respiratory protection equipment can be minimized. By watching workers and monitoring for airborne radioactivity during a job, technicians can suggest methods to prevent creating airborne radioactivity or can warn workers when airborne radioactivity is present.

Appropriate corrective actions can be implemented. As in exposure and contamination control, technicians should explain the actions required to the workers.

The following items should be considered:

- Look for any actions that could create airborne radioactivity.

- Take air samples during jobs in highly contaminated areas or at steps that could create airborne radioactive material during a job.

- Use a continuous air monitor (CAM) during the performance of a job that is likely to create airborne radioactivity.

- Ventilate enclosed areas. 
Notes. . . . 


\section{Overall Job Control Techniques}

2.11.12 Describe overall job control techniques in maintaining control of radiological work.

Overall job control techniques are as follows:

- Establish worker trust and confidence.

- During job coverage, technicians should keep workers within their line of sight, if possible.

- Keep in contact with the workers.

- Remind workers that casks, containers, or systems are not to be opened or work techniques changed without notifying radiological control.

- When an individual's work habits must be corrected, offer the correct method as advice or help.

- Show a positive, helpful attitude toward coworkers. Maintain interest in the job.

- Do not overreact to situations when time is available for levelheaded solutions. 
Notes. . . . 


\section{Stop Work Authority}

2.11.13 State the reasons to stop radiological work activities in accordance with the DOE RCS.

The DOE radiological control standard gives radiological control personnel the authority and responsibility to stop work when

- inadequate radiological controls exist;

- radiological controls are not being implemented;

- radiological hold points are not being satisfied; and

- alarming dosimetry or unexpected dosimetry readings are found.

P313, R2A2 gives authority to RCTs as follows:

- Pause or stop work to ensure that work activities are completed safely.

Exercise your authority to stop work with discretion. Remember that it is your responsibility to ensure that work is performed safely in a radiological environment.

Resumption of radiological work requires approval from the line manager responsible for the work and from the radiological control manager.

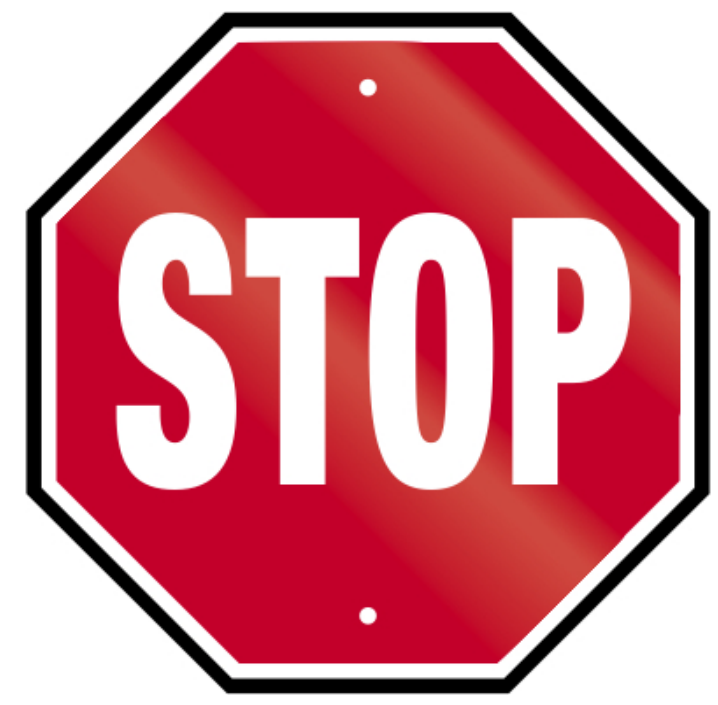




\title{
RCT: Module 2.11, RADIOLOGICAL WORK COVERAGE
}

Course 8777

\author{
July 2017
}




\section{Overview of Lesson}

- Radiological work is usually approved and controlled by radiation protection personnel by using administrative and procedural controls, such as Radiological Work Permits (RWPs). In addition, some jobs will require working in, or will have the potential for creating, very high radiation, contamination, or airborne radioactivity areas. RCTs providing job coverage have an integral role in controlling radiological hazards. 


\section{Terminal Objective}

- Given the course material and participating in a live classroom version of this course, RCT's must demonstrate a basic understanding of RCT: 2.11 RADIOLOGICAL WORK COVERAGE and its applications by completing the quiz at the end of the course. 


\section{Enabling Objectives}

- 2.11.01 - List four purposes of job coverage.

- 2.11 .02 - Explain the differences between continuous and intermittent job coverage.

- 2.11.03 - Given example conditions, identify those that should require job coverage.

- 2.11 .04 - Identify items that should be considered in planning job coverage.

- 2.11.05 - Identify examples of information that should be discussed with workers during pre-job briefings. 


\section{Enabling Objectives}

- 2.11.06 - Describe exposure control techniques that can be used to control worker and technician radiation exposures.

- 2.11.07 - Describe the in-progress radiological surveys that should be performed at LANL under various radiological conditions.

- 2.11.08 - Describe LANL requirements for documentation of in-progress radiological surveys.

- 2.11.09 - Explain actions that should be taken if surveys show radiological conditions significantly different from that expected. 


\section{Enabling Objectives}

- 2.11.10 - Describe contamination control techniques that can be used to limit or prevent personnel and area contamination and/or reduce radioactive waste generation.

- 2.11.11 - Describe job coverage techniques that can be used to prevent or limit the spread of airborne radioactive material.

- 2.11 .12 - Describe overall job control techniques in maintaining control of radiological work.

- 2.11.13 - State the reasons to stop radiological work activities in accordance with the DOE Radiation Control Standard. 


\section{RCT Support Priorities}

- P313, Roles, Responsibilities, Authorities, and Accountability (R2A2) defines R2A2 for all LANL employees.

- P313 Attachment A, Facility Operations $R 2 A 2$ indicates the

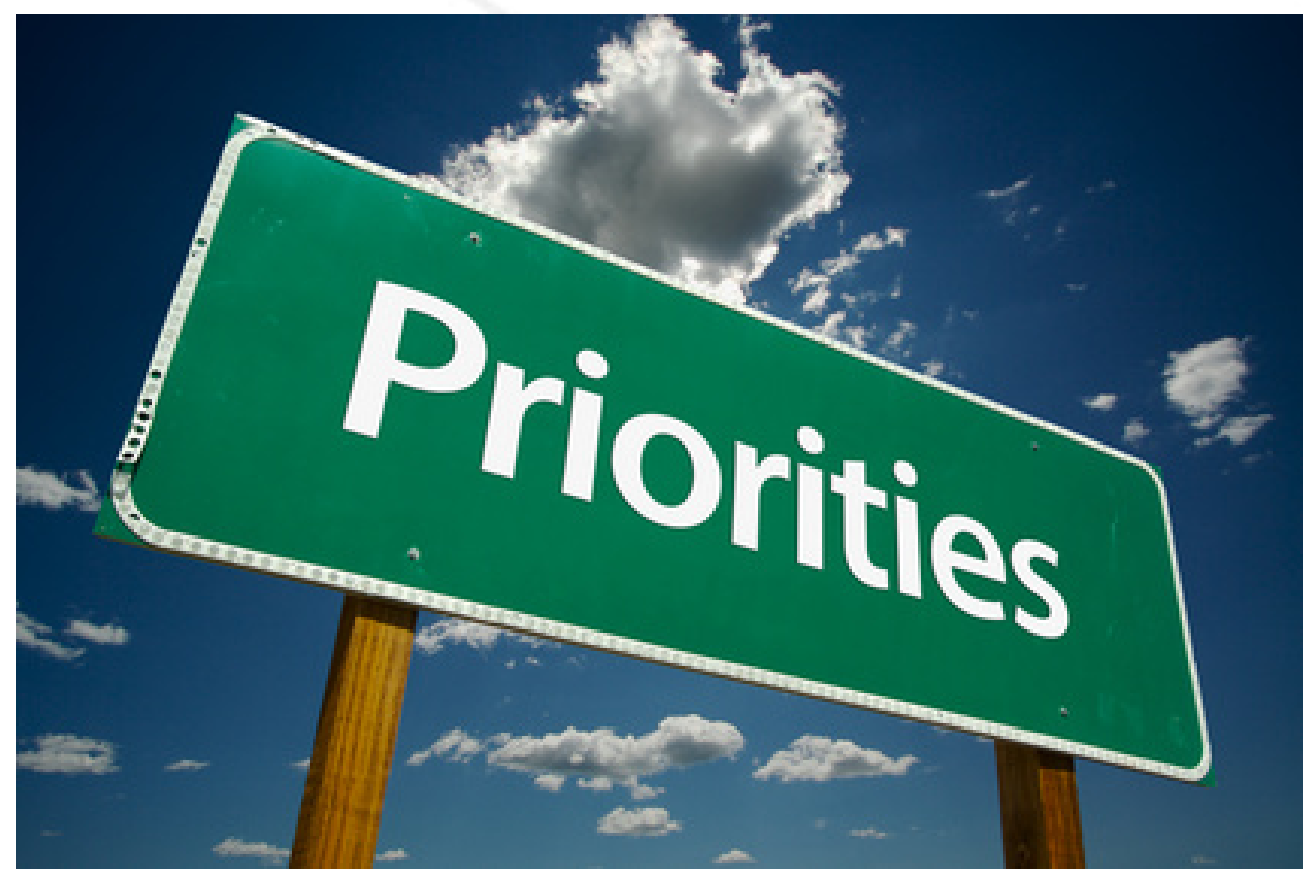
following: The RCT provides radiological support at assigned Laboratory facilities, including (in priority order): emergency response, compliance, facility operability, and programmatic activities. 


\section{P313 Facility Operations R2A2}

\begin{tabular}{|l|l|}
\hline & Radiological Control Technician (RCT) \\
\hline Role & The RCT provides radiological support at assigned Laboratory \\
facilities, including (in priority order): emergency response, \\
compliance, facility operability, and programmatic activities.
\end{tabular}

RCT_2.11_Rad-Wk-Cover_8776_SM,R1.1

\section{UNCLASSIFIED}




\subsubsection{1 - Purpose of RCT Job Coverage}

- Job coverage by RCTs generally has four purposes:

- To ensure that worker's radiation exposures are maintained ALARA and within limits/guidelines

- To minimize the creation and spread of surface contamination.

- To minimize the creation and spread of airborne radioactive material.

- To minimize the creation of radioactive waste.

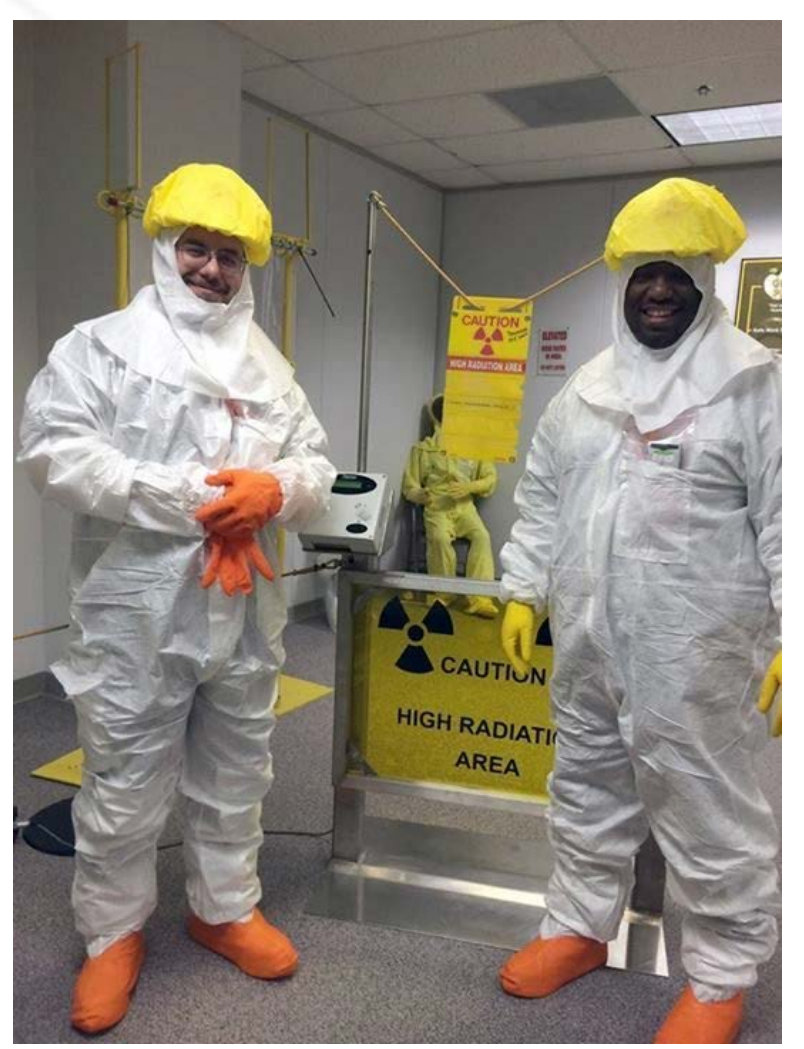




\subsubsection{2 - Continuous and Intermittent Job Coverage}

- Job (or work) coverage can be either continuous or intermittent.

- During continuous job coverage, the technician covers only one job and remains at the job site while work is being performed.

- For intermittent coverage, the technician may cover more than one job, performing periodic checks at various work locations. 


\subsubsection{3 - Areas Requiring Continuous Job}

\section{Coverage}

- Continuous radiological job coverage is required in the following areas:

- High Radiation Area

- Very High Radiation Area

- High Contamination Area

- Airborne Radioactivity Area

- Any areas in which respiratory protection is used for radiation protection purposes.

CAUTION

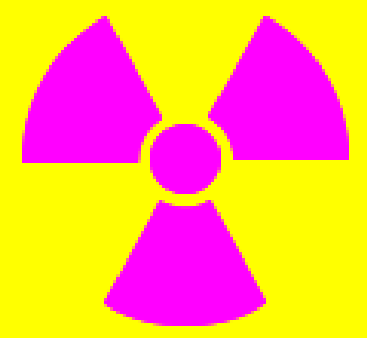

HIGH RADIATION AREA

Potential dose rates

between $0.1 \mathrm{rem} / \mathrm{hr}$ and $1 \mathrm{rem} / \mathrm{hr}$ 


\subsubsection{3 - Conditions Requiring Continuous Job Coverage (cont)}

- Continuous radiological job coverage is required for the following:

- Radiation dose rates in the job area that are high enough to potentially cause workers' doses to exceed administrative control levels in a short time.

- Radiation levels that are expected to increase significantly during the job.

- Radiation levels that are unknown before beginning the job.

- Entry into high-radiation areas. 


\subsubsection{3 - Conditions Requiring Continuous Job Coverage}

- The potential for spreading high levels of contamination or causing airborne radioactivity.

- The potential for a significant increase in contamination or airborne radioactivity levels during the job.

- Inadequate personnel dosimetry for the type or levels of expected radiation (e.g., neutrons or low-range dosimeters).

- Jobs performed by inexperienced workers or by workers unfamiliar with the area or the job. 


\subsubsection{4 - Planning Job Coverage}

- To effectively cover a job, RCTs must plan activities. Actions that should be incorporated in the planning include:

- Determining exactly what workers will be doing.

- Reviewing old surveys, and talking with technicians who have previously covered the same or similar jobs to anticipate anv problem areas.

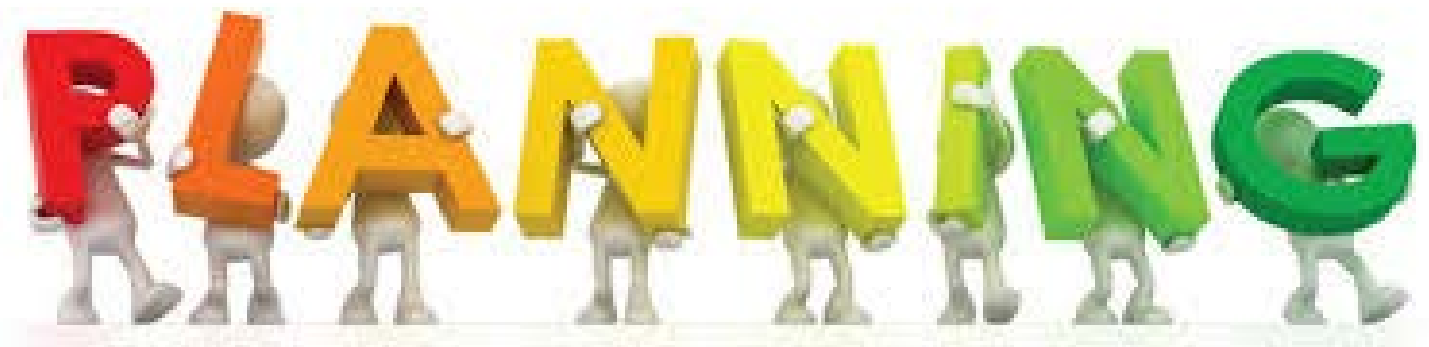




\subsubsection{4 - Planning Job Coverage (cont)}

- Reviewing the area and system on which the work will be performed, or talking with the workers to determine the potential radiological consequences of the tasks associated with the job.

- Ensuring that an adequate survey of the job area has been made.

- Reviewing applicable post-

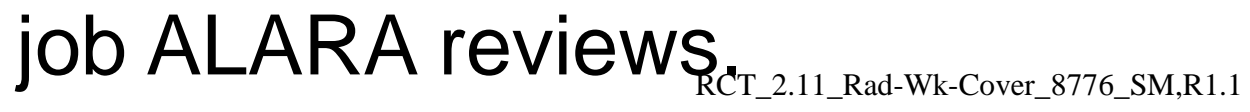

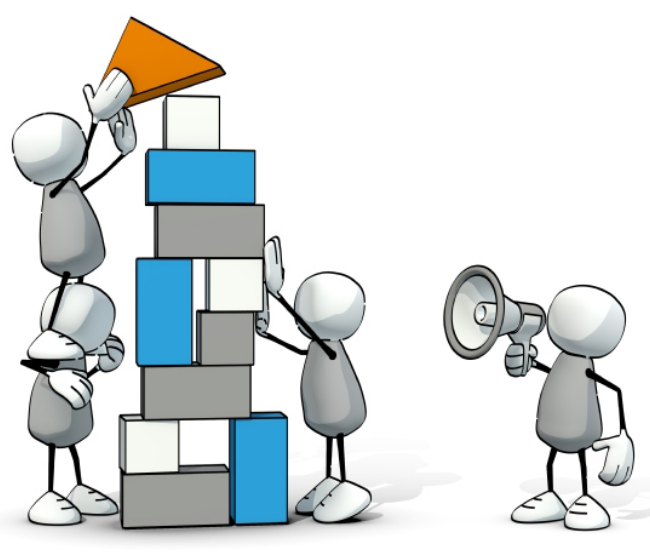




\subsubsection{4 - Planning Job Coverage (cont)}

- Requiring a pre-job survey when sufficient survey documentation is not available. This detailed survey is performed at the job site before the job begins and is used to determine RWP requirements. This survey should include the dose rate, contamination, and representative breathing zone air samples for the areas being accessed. The survey should identify the highest and lowest dose rate areas.

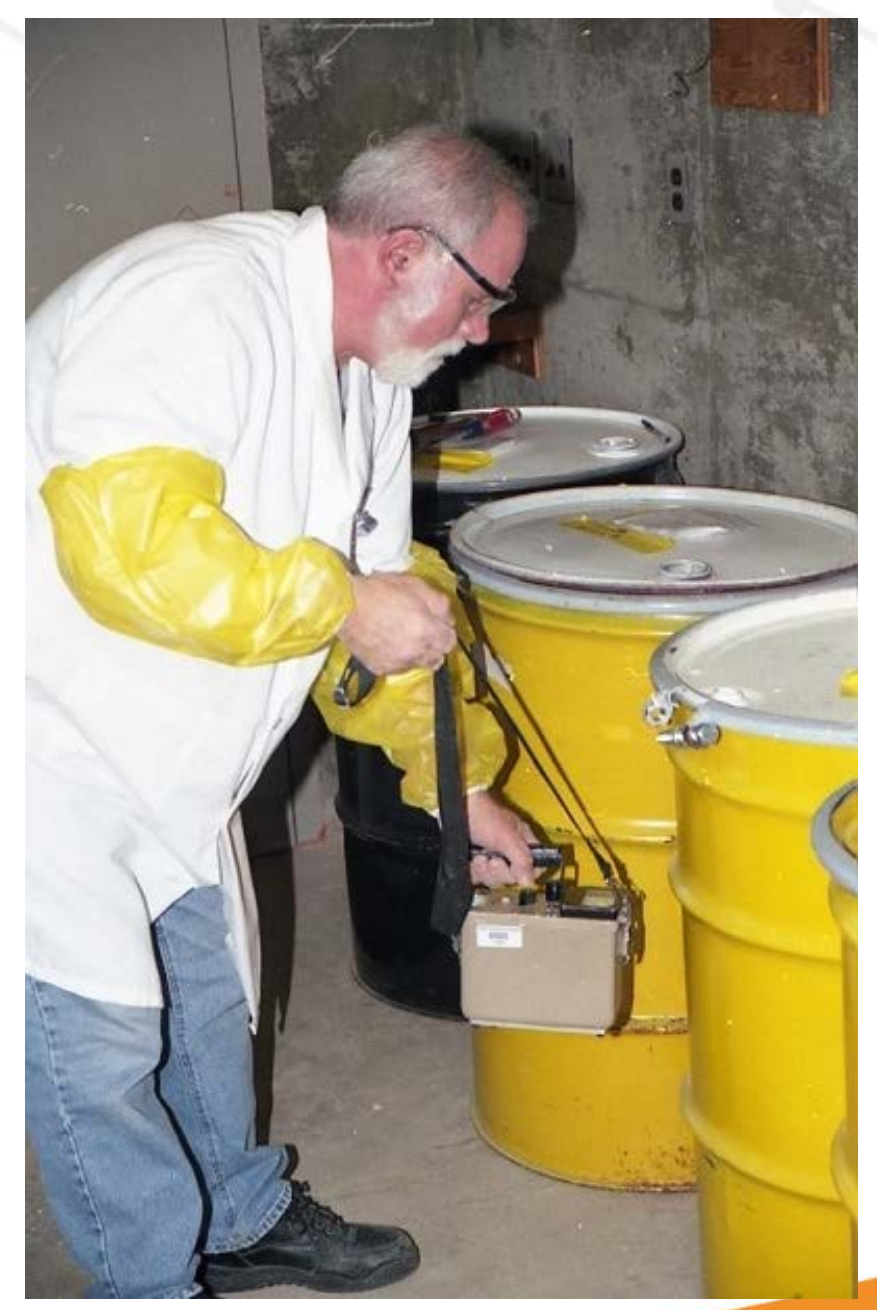




\subsubsection{4 - Planning Job Coverage (cont)}

- Recording the allowable exposure for each worker for jobs in which workers' dose limits could be approached. A good practice is to have this information available at the job site.

- Establishing communication methods with the workers before the job is performed. Workers should know how, when,

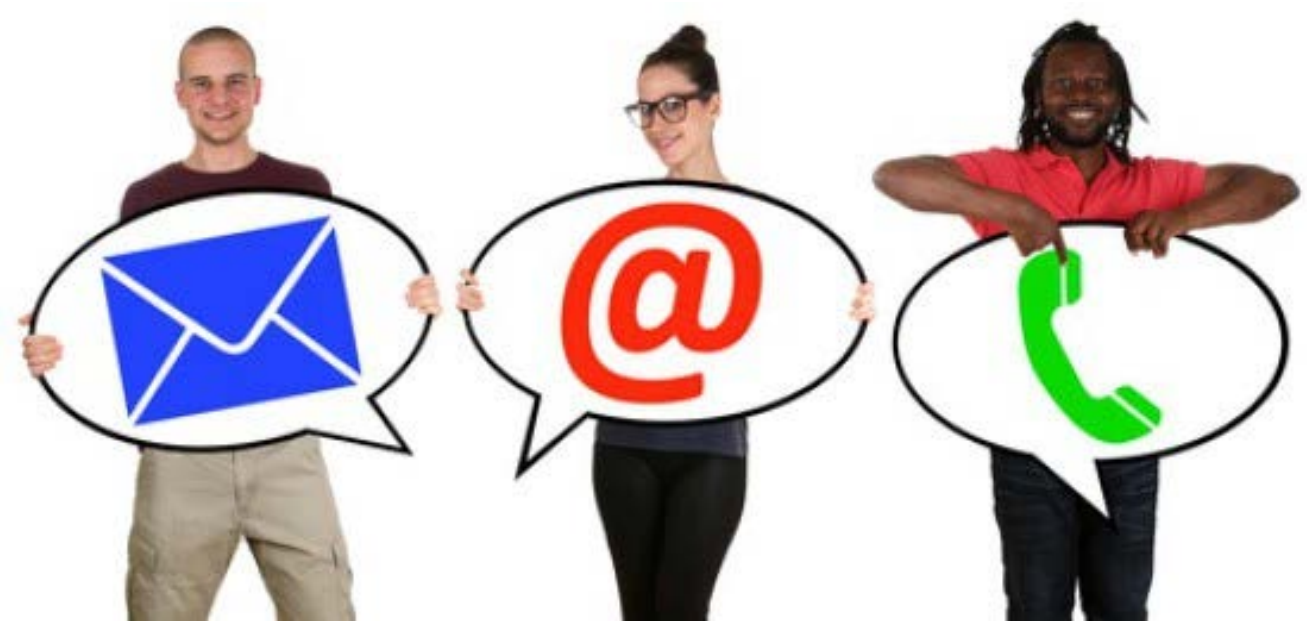
where, and why to contact the RCT. 


\subsubsection{4 - Planning Job Coverage (cont)}

- Communicating with workers, which for most jobs is simply a matter of talking face to face. However, for some jobs, remote communications (e.g., headsets, or a safety line attached to a belt) may be required. Hand signals may be needed when respirators are worn. Two-way portable radios also may be used.

- Establishing a method of communicating with and transferring samples to the radiological control counting lab.

- Arranging for the transfer of samples to the count lab, and obtaining results, which should be made before the job begins. 


\subsubsection{4 - Planning Job Coverage (cont)}

- Having the appropriate equipment available at the job site. Examples include extra dosimeters, a dosimeter charger, air sampler and filters, a survey instrument, A respirator (if needed), a watch or clock for time keeping, and extra gloves.

- Determining waste disposal methods.

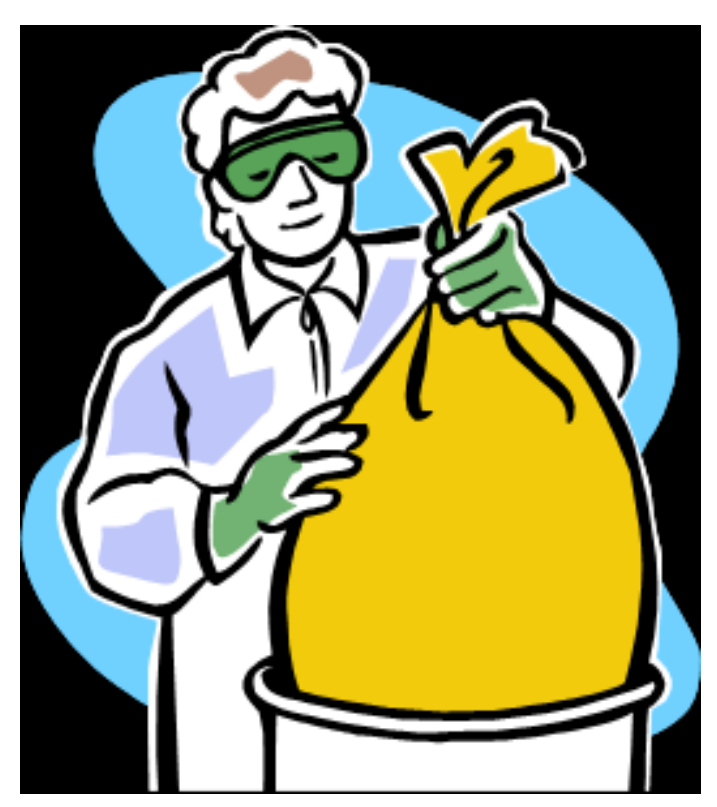




\subsubsection{5 - RWP Pre-Job Briefings}

- Pre-job briefings are conducted by the cognizant RCT and should include the following information:

- The scope of work to be performed.

- Radiological conditions, such as dose rates, contamination levels, and the concentration of airborne radioactivity in the work area.

- An explanation of the probable effect of the job on radiological conditions.

- RWPs and special radiological control requirements.

- RWP limits - conditions, such as contamination or radiation levels that may void the RWP. 


\subsubsection{5 - Pre-Job Briefings (cont)}

- Health Physics/Radiological Control Hold Points

- Other important points, which could include the method of communications that will be used, specifics about special dosimetry or protective clothing, and actions of the technician covering the job.

- Actions and exits to take in an emergency to reduce worker exposure and confusion.

- Worker questions should be answered before work begins.

- The RCT should emphasize radiological safety and the importance of following the RWP and its specific directions. 


\subsubsection{6 - Exposure Control Techniques}

- The techniques in covering a job will depend on the nature of work being done, the radiological conditions present or expected in the work area, and to some extent, the experience of the workers.

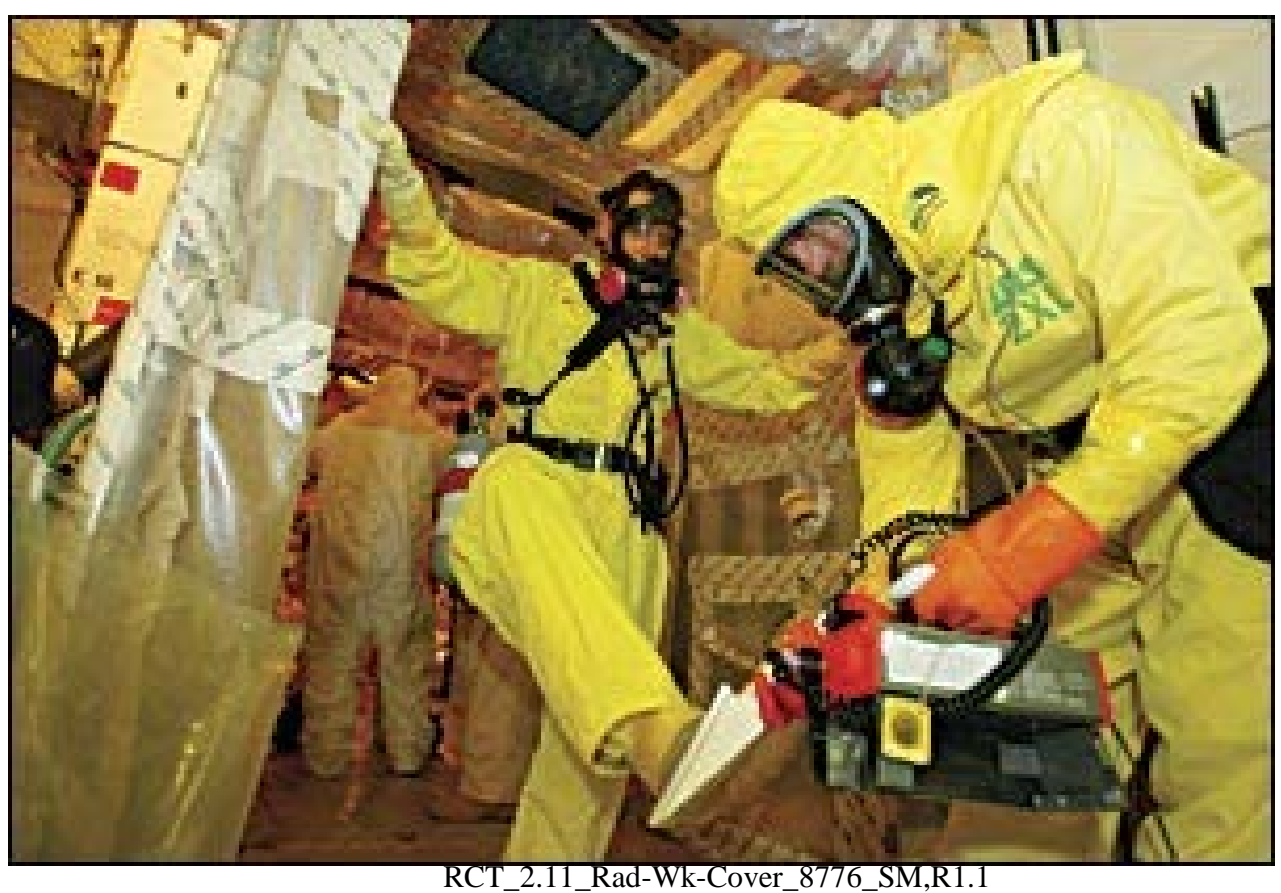

UNCLASSIFIED 


\subsubsection{6 - Exposure Control Techniques (cont)}

- One of the purposes of job coverage is to keep track of the dose received by workers and suggest methods that the workers can follow to keep their doses ALARA.

- Pre-job surveys alone are not always adequate in determining the dose rates that personnel may acquire during the job.

- Many jobs will require that surveys be performed as the job progresses.

- The purpose and type of surveys should be based on the level of the conditions and their probability of change. 


\subsubsection{6 - Exposure Control Techniques (cont)}

- Surveys provide information about current conditions and if the conditions are changing.

- Surveys can identify unusual conditions that may lead to changing job requirements or even stopping the job.

- It is just as important to record the results of job coverage surveys as recording the results of the routine and pre-job surveys.

- Keep personnel in the area informed of the radiological conditions.

- RCTs should explain to the workers why actions are being taken. 


\subsubsection{6 - Exposure Control Techniques (cont)}

- The following is a list of some of the techniques that can be used to help maintain exposure control:

- Wait in low-dose-rate areas when not actually performing the job.

- Periodically read or have workers read their dosimeters.

- Use workers' allowable dose and the dose rate in an area to determine the length of time a worker can spend in the area.

- When using time to control workers' doses, an accurate record of the workers' location with respect to the dose rate must be maintained. 


\subsubsection{6 - Exposure Control Techniques (cont)}

- Write down the workers' location and time in that location when time keeping.

- Relying on memory can be inaccurate. Record the times in the area.

- Observe the location of workers' dosimetry with respect to the location of the radiation source.

- Ensure that workers leave temporary shielding in place unless they have been authorized to remove the shielding by Radiological Control.

- Technicians performing job coverage should move temporary shielding only after evaluating the effect of such movement and with proper approval. 


\subsubsection{6 - Exposure Control Techniques (cont)}

- Perform your survey as objects are being removed from their shipping container or cask.

- Keep workers from leaning across or over high sources of radiation.

- Prevent workers from picking up sources of radiation with their hands. Use pliers or tongs, and use buckets

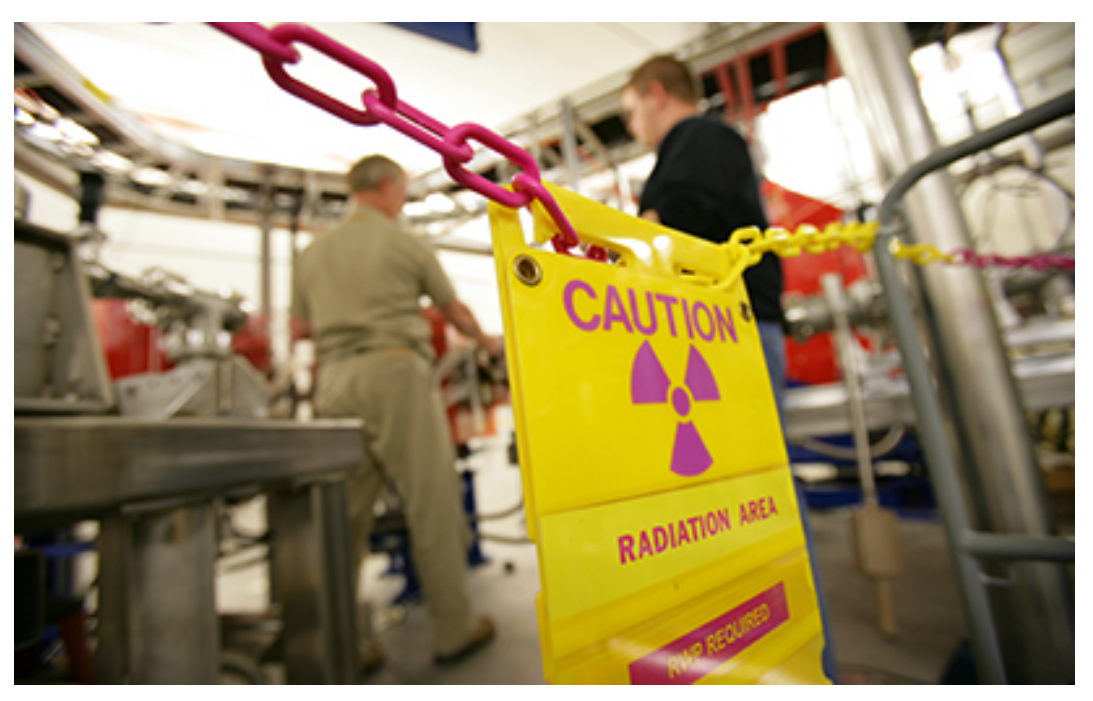
or a plastic bag to carry items. 


\subsubsection{6 - Exposure Control Techniques (cont)}

- Any time casks, equipment, or containers are being opened (or opened further than before), recheck radiation levels, including beta radiation levels.

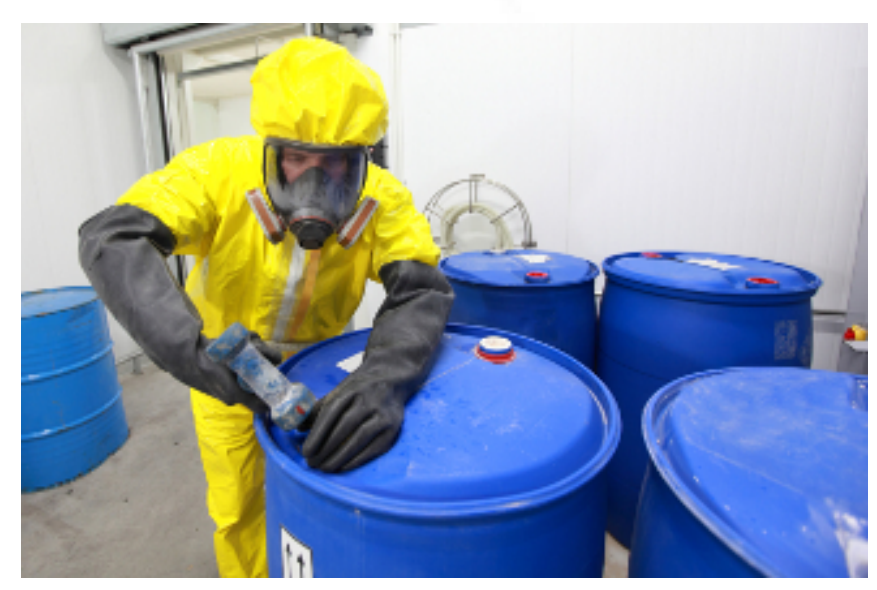




\subsubsection{7 - Radiological Surveys at LANL}

- In-progress radiological surveys should be performed as specified by the controlling technical work document and RWP.

- Radiological control programs require the performance of external radiation, airborne radioactivity, and contamination surveys to determine existing conditions in a given location.

- Maps with sufficient detail to permit identification of original survey and sampling locations should be maintained by the RCT.

- Records should contain sufficient detail to be meaningful even after the originator is no longer available. 


\subsubsection{7 - Radiological Surveys at LANL (cont)}

- Contamination Survey -Contamination surveys characterize workplace conditions, identify areas and/or materials that require radiological posting or labeling, and ensure that no regulated contamination limits are exceeded.

- Airborne Radioactivity Survey - Air monitoring is performed based on the potential for radioactive material to become airborne. Operations that can cause material to become airborne include, but are not limited to cutting, grinding, welding, sanding, or spraying. 


\subsubsection{7 - Radiological Surveys at LANL (cont)}

- External Radiation Survey -Radiation surveys provide information concerning external sources of whole body and/or extremity exposure to personnel.

- Survey Frequency Requirements - The survey frequency should be established based on radiological conditions, probability of change in conditions, and occupancy. Surveys should be performed before, during, and after work that could cause significant changes in radiological conditions. 


\subsubsection{7 - Radiological Surveys at LANL (cont)}

- When to Conduct Contamination Surveys - An integral part of the monitoring program is the collection of survey data by contamination surveys of the workplace and the survey of materials and equipment before they are released or transferred from one location to another.

- The primary methods for detecting contamination at the Laboratory are smear surveys, large-area swipe surveys, and direct frisk (including floor monitoring).

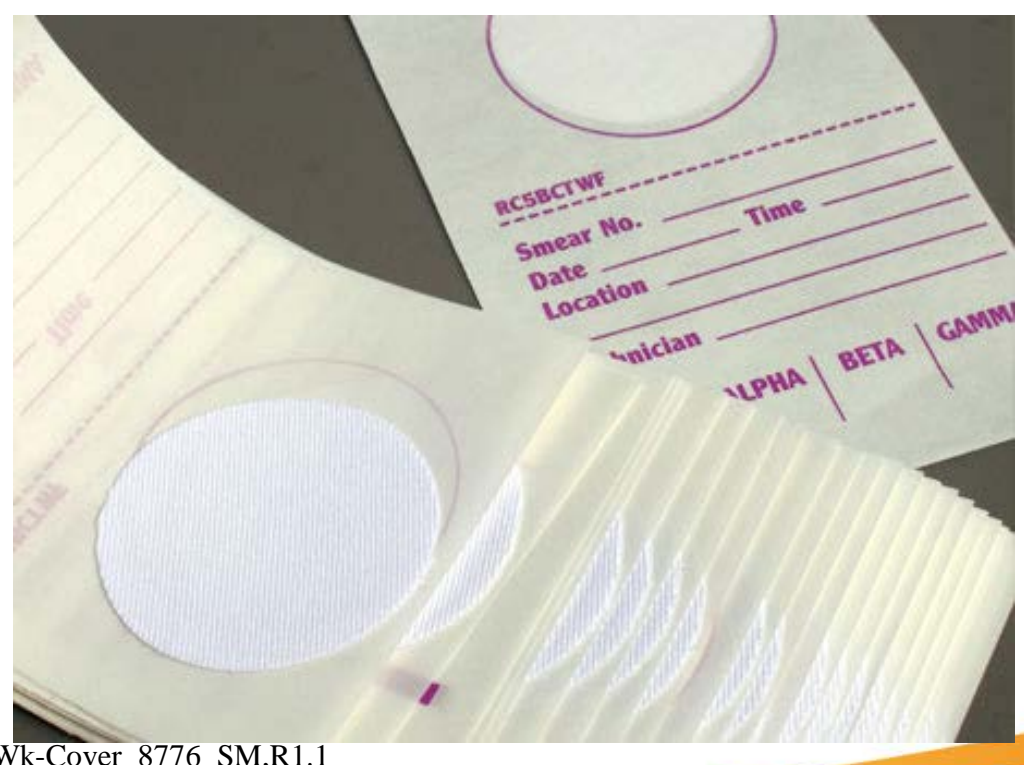




\subsubsection{7 - Survey Frequency at LANL}

- The frequencies of routine contamination surveys are listed in RP-SOP-020, Contamination Monitoring Standard. The following frequencies are required:

- Daily, at contamination area control points, change areas, or step-off pads when in use, or per shift in high-use situations.

- Daily, in office space located in Radiological Buffer Areas (RBAs) established for contamination control.

- Daily, in lunch rooms or eating areas near RBAs established for contamination control.

- Weekly, in routinely occupied RBAs established for contamination control. 


\subsubsection{7 - Survey Frequency at LANL (cont)}

- Weekly, or upon entry if entries are less frequent, in areas where radioactive materials are handled or stored.

- During initial entry into known or suspected Contamination Area, periodically during work, at completion of job, or as specified in a RWP.

- After a leak or spill of radiological materials.

- Weekly, in areas identified as either being contaminated or having the potential for being contaminated with hot particles, and daily, during periods of work that may result in the generation of hot particles. 


\subsubsection{8 - Documentation of In-Progress Radiological Surveys}

- Radiological control personnel should maintain logs to document radiological occurrences, status of work activities and information that should be communicated to all personnel.

- Field notes of survey results should be made for later documentation.

- Good practice dictates that all surveys should, at a minimum, be documented on the appropriate map 


\subsubsection{8 - Documentation of In-Progress Radiological Surveys (cont)}

- Documentation of radiological surveys includes the following elements:

- Date and time

- Locations and map

- Name and signature of the surveyor

- Instrument model and number

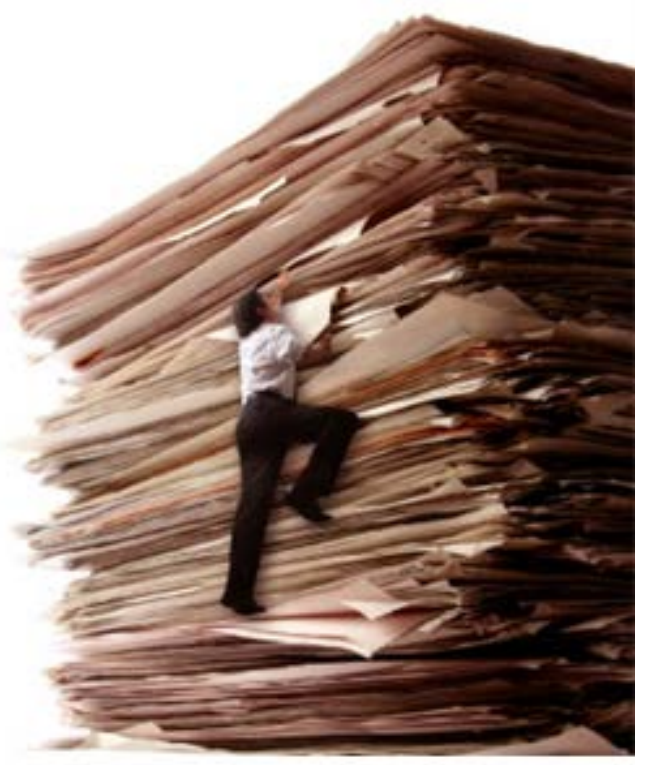

- Purpose and reference to a specific RWP if applicable

- Results 


\subsubsection{8 - Documentation of In-Progress Radiological Surveys (cont)}

- Documentation for Airborne Radioactivity Surveys includes

- Flow rates

- Duration of sampling

- Documenting results is critical, even if no contamination is detected. These documents become part of the Laboratory's permanent record of radiological conditions. Forms must be carefully filled in with all requested information. Any pertinent special notes that would aid the reader in interpreting the results, or planning future actions should also be added. 


\subsubsection{9 - Unexpected Radiological Conditions}

- If previously undiscovered contamination is detected during contamination surveys, more smears and swipes should be taken so that the extent and levels of the contamination can be determined.

- If contamination is detected, direct instrument surveys, large-area-swipe surveys, and/or comprehensive smear surveys are used to delineate the radiological boundaries. Large-area swipes are used to provide a quick estimate of the extent of contamination in a known or suspected contaminated area. New postings may be required for areas with significant readings. 


\subsubsection{9 - Unexpected Radiological Conditions}

- When higher-than-expected levels are found, the RCT should evacuate the area and determine why the rates are higher. If higher radiation levels are indicated, the RCT will investigate the reason for the increase.

- If the conditions are different enough to warrant a change in the protection requirements, stop work until the RWP can be revised and approved.

- Any radioactive material outside a Contamination Area must be identified with suitable tags or labels. If you find unlabeled radioactive material in a Controlled Area, this radiological occurrence must be reported. 


\subsubsection{0 - Contamination Control Techniques}

- By observing the actual performance of the job, RCTs can suggest methods that could help prevent the spread of contamination from one area to another and could lessen the probability of personnel contamination.

- Watch the workers.

- Wipe down and drain system components that are being repaired before the system is opened.

- Ensure that workers follow procedures for transferring material from the radiological area to either a Radiologically Controlled Area or a clean area.

- Control the removal of equipment from work areas. 


\subsubsection{0 - Contamination Control Techniques (cont)}

- Ensure that workers follow proper procedures to minimize the contamination of tools and equipment.

- Watch for the movement of crane rigging, air or water hoses, electric leads, and extension cords into and out of contaminated areas.

- Secure electrical lines and hoses going into Contaminated Areas to eliminate the possibility of movement in or out.

- Have workers remove their outer layer of protective clothing a few feet from the step-off pad area.

- Reduce the creation of radioactive waste. 


\subsubsection{1 - Airborne Radioactivity Control}

- When the creation and spread of airborne radioactivity can be controlled, the use of respiratory protection equipment can be minimized.

- By watching workers and monitoring for airborne radioactivity during a job, technicians can suggest methods to prevent creating airborne radioactivity or can warn workers when airborne radioactivity is present.

- Appropriate corrective actions can be implemented. As in exposure and contamination control, technicians should explain the actions required to the workers. 


\subsubsection{1 - Airborne Radioactivity Control (cont)}

- The following items should be considered:

- Look for any actions that could create airborne radioactivity.

- Take air samples during jobs in highly contaminated areas or at steps that could create airborne radioactive material during a job.

- Use a continuous air monitor (CAM) during the performance of a job that is likely to create airborne radioactivity.

- Ventilate enclosed areas. 


\subsubsection{2 - Overall Job Control Techniques}

- Establish worker trust and confidence.

- During job coverage, technicians should keep workers within their line of sight, if possible.

- Keep in contact with the workers.

- Remind workers that casks, containers, or systems are not to be opened or work techniques changed without notifying radiological control. 


\subsubsection{2 - Overall Job Control Techniques}

- When an individual's work habits must be corrected, offer the correct method as advice or help.

- Show a positive, helpful attitude toward co-workers. Maintain interest in the job.

- Do not overreact to situations when time is available for levelheaded solutions. 


\subsubsection{3 - Stop Work Authority}

- The DOE Radiological Control

Standard gives Radiological Control personnel the authority and responsibility to stop work when

- Inadequate radiological controls exist

- Radiological controls are not being implemented

- Radiological hold points are not

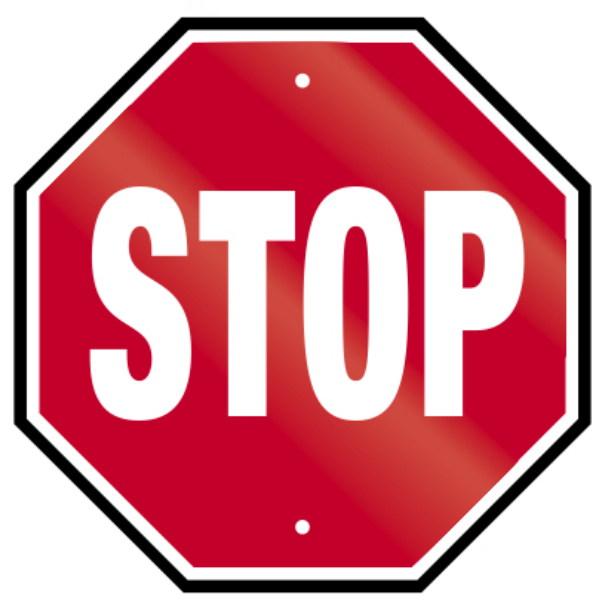
being satisfied

- Alarming dosimetry or unexpected dosimetry readings are found 


\subsubsection{3 - Stop Work Authority (cont)}

- P313, R2A2 gives authority to RCTs as follows:

- Pause or stop work to ensure that work activities are completed safely.

- Exercise your authority to stop work with discretion. Remember that it is your responsibility to ensure that work is performed safely in a radiological environment.

- Resumption of radiological work requires approval from the line manager responsible for the work and from the Radiological Control Manager. 